\title{
Modal Meinongianism: Conceiving the Impossible
}

\author{
Franz Berto \\ Institute for Logic, Language and Computation (ILLC) \\ University of Amsterdam \\ F.Berto@uva.nl
}

It is impossible to construct a regular polygon of nineteen sides with ruler and compass; it is possible but very complicated to construct one of seventeen sides. In whatever sense I can imagine the possible construction, I can imagine the impossible construction just as well.

David Lewis, On the Plurality of Worlds

\section{Comprehension and Intentionality}

In 2005 Graham Priest reinvented Meinongianism: the view that some objects do not exist, thus existence, pace Quine (1948), is not captured by the quantifier. He did it by publishing a slim book, Towards Non-Being, which included a new approach to one of Meinongianism's core problems: which conditions characterize objects? Let me explain.

Any Meinongian theory needs some principle stating which objects are admitted by the theory, and which properties they can have. Principles of this kind have been called Characterization or (in analogy with set theory) Comprehension Principles, and the problem of finding a good one has been called the Characterization Problem.

Why problem? In its naive version (of which it is unclear whether it was ever endorsed by anyone), Meinongianism subscribes to what Parsons (1980) called an 'Unrestricted Comprehension Principle' for objects: 
(UCP) For any condition $A[x]$, with free $x$, some object satisfies $A[x]$.

The principle looks intuitive. Take such features as $x$ is a detective, $x$ lives in Victorian London at 221b Baker Street, $x$ is Moriarty's arch-enemy, $x$ has amazing powers of observation and deduction, $x$ always wears a deerstalker..., etc. If $A[x]$ stands for the conjunction of the corresponding predicates, then according to the (UCP) an object is characterized by $A[x]$. Call it 'Sherlock Holmes', $h$. Then Holmes really has the relevant properties, $A[h]$.

This cannot work, however. As remarked by Priest (2005), p. xix, via the (UCP) one can prove anything whatsoever. Let $A[x]$ be $x=x \wedge B$, with $B$ an arbitrary formula. By the (UCP), something, $b$, is such that $b=b \wedge B$, from which $B$ follows by Conjunction Elimination. The Naive Comprehension Principle of set theory, granting a set for any condition $A[x]$, also produced notorious problems. Mathematicians who did not want to abandon Cantor's paradise had to work around the Principle in order to fix it. So did philosophers reluctant to abandon Meinong's paradise (?) work around the (UCP) in order to fix it.

Nuclear Meinongians, Parsons (1980), Routley (1980), Jacquette (1996), limited the Principle to a restricted vocabulary. They distinguished between two kinds of predicates (with the corresponding properties), called nuclear and extranuclear, and only conditions $A[x]$ including just nuclear predicates were allowed to deliver objects. It was essential that existence be extranuclear.

Dual copula Meinongians, Zalta (1983), Zalta (1997), made a distinction between two ways in which things can be ascribed properties: ordinary predication expressing property-instantiation or exemplification, and encoding. Encoding did not in general entail exemplification. The relevant nonexistent objects could then encode features of any kind - provided $A[x]$ did not mention encoding itself, otherwise a kind of self-referential paradox would ensue (see Rapaport (1978)).

Priest (2005), pp. xix and 84, came up with (what Berto (2012) later on called) a Qualified Comprehension Principle:

- (QCP) For any condition $A[x]$, with free $x$, some object satisfies $A[x]$ at some world.

Reference to worlds is embedded in the Principle; thus, since Berto (2008) the view has come to be called 'modal Meinongianism'. There is no restriction at all on $A[x]$ in the (QCP); and 'satisfying' is not encoding: it expresses ordinary property-instantiation. However, when object $O$ is characterized as $A[x], A[o]$ may not hold at the actual world (though it may). It holds at some 
world or other, that is, at those worlds that realize the situation envisaged by the person who uses the characterizing condition.

Speaking of 'envisaging' takes us to the core of the issue I want to discuss. The subtitle of Priest's book was: The Logic and Metaphysics of Intentionality. On the one hand, the book aimed to give a general treatment of the logic and semantics of intentional states: representational states of the mind which are directed to objects, scenarios, or circumstances. ${ }^{1}$ In particular, the semantics invalidated various intuitively undesirable forms of logical omniscience, that is, of logical closure properties of the relevant mental states.

On the other hand, intentionality itself was taken, as it often is by Meinongians, as a main motivation for accepting nonexistent objects. Meinongians have conjectured that (current, actual) nonexistents may be admitted by considering past and future times, or unrealized possibilities. But it is fair to say that the most promising candidates for nonexistence come from the realm of intentionality. This is also how Priest motivated the (QCP):

Cognitive agents represent the world to themselves in certain ways. These may not, in fact, be accurate representations of this world, but they may, none the less, be accurate representations of a different world. For example, if I imagine Sherlock Holmes, I represent the situation much as Victorian London (so, in particular, for example, there are no aeroplanes); but where there is a detective that lives in Baker St, and so on. The way I represent the world to be is not an accurate representation of our world, but our world could have been like that; there is a world that is like that. (Priest (2005), p. 84)

Although here Priest speaks of a way of representing the world such that our world could have been like that, in the (QCP) above "world" does not stand just for possible world, that is, way things could be or have been. The worlds semantics of Towards Non-Being included impossible worlds: ways things could not be or have been (Berto (2013), Kiourti (2010), Nolan (2013)).

Priest expanded on a technique used by Rantala (1982) in epistemic logic in order to get rid of logical omniscience phenomena. He had in the language of his theory intentional operators of the kind ' $x \Psi A$ ' ( $x \Psi$ 's that $A$ :

\footnotetext{
${ }^{1}$ Priest dealt both with intentional states directed towards objects, such as fearing John, dreaming of Obama, imagining a tree in the garden, and with so-called propositional states, such as fearing that John comes along, dreaming that Obama wins the elections again, imagining that the tree starts talking to me. In the following, we will deal only with the latter kind of states.
} 
hopes that $A$, fears that $A$, believes that $A$ ), interpreted as restricted quantifiers over possible and impossible worlds. He admitted anarchic impossible worlds not closed under any non-trivial relation of logical consequence (he called them, thus, "open worlds"). By having truth conditions allowing access to such worlds, the relevant operators easily defied closure under nearly any nontrivial consequence relation in their turn (it being clear that, if one wanted, conditions on accessibility could be added to give to specific $\Psi$ 's more logical backbone).

Accessibility relations in the semantics were interpreted, thus, in an intentional sense: ' $w R_{\Psi}^{x} w_{1}$ ' meant that world $w_{1}$ is cognitively accessed by intentional agent $x$, who, at world $w, \Psi$ 's that something is the case. It is true at $w$ that $x \Psi A$ iff $A$ is true at all the accessed $w_{1}$ - which may be possible, or impossible.

The first edition of Priest's book largely took for granted that impossible worlds are cognitively accessible. That is, we can think about the absolutely impossible: that which holds at no possible world whatsoever. ${ }^{2}$ But the greatly expanded and revised second edition of the book, published in mid2016, has more to say on this matter - and rightly so, because a venerable philosophical tradition denies that we can intend the impossible.

The most quoted authority here is Hume, who formulated what I will call, stealing throughout this paper a label that has been used for something else, Hume's Principle (HP):

'Tis an establish'd maxim in metaphysics, that whatever the mind clearly conceives includes the idea of possible existence, or in other words, that [HP:] nothing we imagine is absolutely impossible. (Treatise, I, ii, 2$)^{3}$

Hume took the absolutely impossible to coincide with the logically impossible, but we need not follow him on this. What matters is that it not be what is at times called the nomologically impossible: the impossible relative to some body of natural laws, like the laws of physics or biology. All

\footnotetext{
${ }^{2}$ Philosophers debate on the nature of absolute necessity, and thus impossibility, but it is fair to say that the three main kinds of absolute necessities/impossibilities are usually taken to be the logical, the mathematical and the metaphysical. I will not get into the issue of whether one of them is reducible to another (e.g., the mathematical to the logical, as it is for logicists).

${ }^{3}$ As Yablo (1993), p. 4, has remarked, in spite of that "in other words" it is doubtful that here Hume is really giving the same maxim twice. It is one thing to say that, when we (clearly) conceive something, what is conceived comes with the idea that it could exist embedded in by default. It is another thing to say that we can only imagine the possible. It is the latter claim that will be on stage in the following, as the target (HP).
} 
parties in the debate around (HP) agree that we can conceive the biologically or physically impossible, e.g., my jumping 1 mile up in the air, or (if Einstein was right) a starship's moving faster than the speed of light. So, for instance, in Positivismus und Realismus Schlick maintained that, while the merely practically impossible is conceivable, it is the logically impossible, such as a contradiction, which is not. ${ }^{4}$

Although the issue pops up in various parts of the 2016 edition of his book, Priest addresses it mainly in Chapter 9, called Possibility, Impossibility and Conceivability. The purpose of this paper is to expand on Priest's arguments against (HP). Drawing largely on Berto and Schoonen (2017), ${ }^{5}$ I will defend the view that we can conceive the impossible. But I will try to tidy up a couple of loose ends in Priest's line of argumentation, and to develop in greater detail a plausible view of how such conceiving is to be understood. I will describe two different conceptions of conceiving, which, borrowing terminology from Kung (2014), I will call the telescopic and the stipulative (if that reminds you of Kripke, you are on the right track). I will argue that the modal Meinongian should subscribe to the latter, and that the latter is independently more plausible than the former anyway.

A defense of the view that we can conceive the impossible is crucial to the modal Meinongian research program. If we cannot, the whole apparatus of impossible worlds becomes pointless as a way to give a semantics of intentionality. The modal Meinongian need not dispute the weaker claim that representing a situation in our mind in a certain way may often provide good, albeit defeasible, evidence to the effect that the situation is possible. As Yablo says, "in slogan form: conceiving involves the appearance of possibility" (Yablo (1993), p. 5). What needs to be disputed is the stronger (HP), the claim that we cannot conceive the impossible. ${ }^{6}$

I will not say much on the (way stronger) claim that any impossibility is conceivable - aside from the following remark: ${ }^{7}$ it may seem that, in a sense, the modal Meinongian view is committed to the way stronger claim as well (and Priest is sympathetic to that in the aforementioned Chapter 9, esp. p. 194). Otherwise, why have (in principle, accessible) impossible worlds of all

\footnotetext{
${ }^{4}$ Contradictions are often invoked as a paradigmatic case of absolute impossibility, and will come handy later on, too. The example may not sound good in the context of a discussion of Priest's work, given that he is (in)famous for believing that some contradictions are true. However, modal Meinongianism can be formulated as a consistent theory: one can be a modal Meinongian without thereby being a dialetheist.

${ }^{5}$ I am very grateful to the Editors of Synthese for allowing me to reuse that material.

${ }^{6}$ Arguments for the claim that we can conceive impossible situations can be found in Byrne (2007), Fiocco (2007), Jago (2014).

${ }^{7}$ Triggered by a nice suggestion by two anonymous reviewers.
} 
sorts? But one may retort that having logically anarchic worlds of any kind in the semantics is just a practical choice, motivated by the vague boundaries of what we can, in general, conceive. It may be that some impossibilities are just inconceivable, for the same reason that some possibilities are inconceivable, namely that the logical, cognitive or computational complexity of the relevant scenario is just too large for our finite human minds. Where to put the complexity boundary is a difficult issue better left to empirical psychology, and it may be that a fuzzy answer is the best we can hope for. In a logical and semantic modeling like the one aimed for in Priest's book, one may thus safely bracket the issue by being extremely generous with the supply of anarchic worlds one works with.

\section{Minimal Conceiving}

Of the two notions involved in (HP), possibility is nowadays reasonably under control after the Twentieth Century development of possible worlds semantics. Conceivability is in a messy state. In Towards Non-Being II, p. 192, Priest starts by understanding conceivability in a rather minimal sense. He draws on the Oxford English Dictionary, according to which to conceive is "to take or admit into the mind, to form in the mind, to grasp with the mind". Given this characterization, he then claims that he can conceive of "anything that can be described in terms that I understand" (p. 194).

The weaker the relevant notion of conceivability, the harder it is to argue that we cannot conceive impossibilities. And conceivability, in such a minimal sense connected to 'grasping with the mind' or 'understanding a description of something', seems to me clearly to allow us cognitive access to the impossible. To deny this, one would seem to be forced to make one of two moves: (1) claim that linguistic representations allegedly describing impossibilities, such as logical falsities, actually are meaningless s so that there is nothing for us to grasp; or (2) claim that although these are meaningful, we cannot understand them.

As a general thesis the latter is simply incredible in the face of the compositionality of learnable languages. Let $P$ be any simple, meaningful, intelligible sentence, such as 'This table is round'. Surely $P$ cannot become unintelligible because we stick a negation in front of it; so $\neg P$ must be intelligible, too. And surely two such sentences cannot deliver an unintelligibility once we conjoin them, $P \wedge \neg P$. So the latter must be intelligible, too.

Someone who came close to making the first claim is Wittgenstein (1922). I say 'came close', because for Wittgenstein's Tractatus tautologies, logical truths, and their negations, logical falsities, are notoriously sinnlos (4.461). 
They "say nothing" (Ibid.). However, even for Wittgenstein they "are, however, not senseless [unsinnig]" but "part of the symbolism in the same way that ' 0 ' is part of the symbolism of arithmetic" (4.462). There is a debate among Wittensteinians, on what the difference between sinnlos and unsinnig amounts to, but we need not enter into this. One straightforward interpretation of the Wittgensteinian view, phrased in the contemporary terminology of possible worlds, is that the informative job of a sentence is to split into two the totality of possible worlds: those in which the sentence is true and those in which it is false. The former group is taken as giving the proposition expressed by the sentence in standard possible worlds semantics. But then tautologies and their negations, being true everywhere and nowhere in the modal space respectively, don't split, and turn out to be uninformative: "I know, e.g., nothing about the weather, when I know that it rains or it does not rain" (4.461).

Even if one buys the view that logical truths and falsities are uninformative, ${ }^{8}$ though, that does not make them meaningless. Even if the distinction between saying and showing at the core of the Tractatus is right (and some, including perhaps the later Wittgenstein, may doubt it), that $P \vee \neg P$ and $P \wedge \neg P$ show something about the logical form of reality rather than informing us of what obtains in it, does not make them meaningless strings, provided that $P$ is meaningful to begin with.

This is one of the few issues on which Priest and Quine, who otherwise disagree on lots of things in logic and ontology, may come to an agreement. Quine makes the point in On What There Is, as a response to fictional philosopher Wyman, sometimes taken as representing Meinong's view. Wyman believes that things like Pegasus ought to be admitted in our ontological catalogue, as possibilia, for otherwise it would make no sense to even say that Pegasus is not. By parity of reasoning, objects Quine, we ought to admit the round square cupola on Berkeley College; otherwise, it would make no sense to even say that it is not. But accepting this, claims Quine, brings inconsistency. Wyman reacts by declaring that inconsistent conditions are just meaningless. I find Quine's reply spotless:

Certainly the doctrine [of the meaninglessness of contradictions] has no intrinsic appeal; and it has led its devotees to such quixotic

\footnotetext{
${ }^{8} \mathrm{I}$ do not buy this view either. Take a cognitive (as opposed to merely environmental) conception of information, and consider what can be learned by a rational, finite and fallible agent - one of us. We can learn that a complex formula, whose truth value we were ignorant of until we computed its long truth table, is a tautology. For all we knew before carrying out the computation, the formula's being false was a way things could be. In this sense, pace Wittgenstein (6.1251), there are surprises in logic. A beautiful book defending this view is Jago (2014).
} 
extremes as that of challenging the method of proof by reductio ad absurdum - a challenge in which I sense a reductio ad absurdum of the doctrine itself.

Moreover, the doctrine of meaninglessness of contradictions has the severe methodological drawback that it makes it impossible, in principle, ever to devise an effective test of what is meaningful and what is not. It would be forever impossible for us to devise systematic ways of deciding whether a string of signs made sense - even to us individually, let alone other people - or not. For it follows from a discovery in mathematical logic, due to Church [1936], that there can be no generally applicable test of contradictoriness. (Quine (1948), pp. 34-5)

In What Is So Bad About Contradictions, Priest is on the same page:

If contradictions had no content, there would be nothing to disagree with when someone uttered one, which there (usually) is. Contradictions do, after all, have meaning. If they did not, we could not even understand someone who asserted a contradiction, and so evaluate what they say as false (or maybe true). We might not understand what could have brought a person to assert such a thing, but that is a different matter and the same is equally true of someone who, in broad daylight, asserts the clearly meaningful 'It is night'. (Priest (1998), p. 417)

\section{Conceiving as Imagining}

There appears to be a more substantive sense of 'conceiving' - one that could be taken as lending some support to (HP). Right after resorting to the aforementioned minimal sense of 'conceiving', Priest adds:

I intend to use conceive here as roughly synonymous with imagine: the sort of imagination employed by scientists, mathematicians, philosophers, novelists, political reformers, theologians, visionaries, and so on [Fn: OED, to imagine: 'to form a mental image of, to represent to oneself in imagination, to create as a mental conception, to conceive']. In imagination, a state of affairs or an object is brought before the mind, and may be considered, enjoyed, its consequences thought through, and so on. (Priest (2005), p. 192, last italic mine) 
Now this sense of 'conceiving' as 'imagining a state of affairs' seems to be more substantive than merely grasping the meaning of a sentence. It is close enough to a notion one can find in Yablo (1993), Chalmers (2002), and dubbed by the latter "positive conceivability". Positively conceiving that $\mathrm{S}$ is understood as a mental operation different from merely supposing or assuming that S, as when we make an assumption in a mathematical proof. Instead, we represent a situation, or a state of affairs, in our mind, a configuration of objects and properties of which $\mathrm{S}$ is a truthful description:

Positive notions of conceivability require that one can form some sort of positive conception of a situation in which $\mathrm{S}$ is the case. One can place the varieties of positive conceivability under the broad rubric of imagination: to positively conceive of a situation is to imagine (in some sense) a specific configuration of objects and properties. [...] Overall, we can say that $\mathrm{S}$ is positively conceivable when one can imagine that $\mathrm{S}$ : that is, when one can imagine a situation that verifies S. (Chalmers (2002), p. 150)

Similarly, Yablo (1993) has it that the conceivability of S amounts to the imaginability of a world verifying $\mathrm{S}$ (he grants that we do not imagine the relevant world in all detail; we will come to issues of detail later on). And it seems to me that something like this is the notion typically at issue in debates around (HP) (see e.g. Hill (1997), Gendler and Hawthorne (2002), Stoljar (2007), Kung (2010), Balcerak Jackson (2016)).

Characterizing (the relevant) imagination is in its turn difficult. The best that can be done, I think, is to point at some features that make conceivability-as-imagination differ from alternative intentional states. ${ }^{9}$ Thus, imagining that $P$ is distinct from believing that $P$ in that one who imagines a situation making $P$ true does not thereby commit to the actuality of that situation. Another difference (see e.g. Nichols and Stich (2003), Wansing (2015)) is that, although there can be involuntary exercises of it, imagining can be voluntary in ways in which believing cannot: the agent just sets out to represent a certain scenario. So I can imagine that New York is in Canada but I cannot make myself believe it, for I have overwhelming evidence of the contrary.

\footnotetext{
${ }^{9}$ I agree with Yablo on this: "Almost never in philosophy are we able to analyze an intentional notion outright, in genuinely independent terms: so that a novice could learn, say, what memory and perception were just by consulting their analyses. About all one can normally hope for is to locate the target phenomenon relative to salient alternatives, and to find the kind of internal structure in it that would explain some of its characteristic behavior." (Yablo (1993), pp. 25-6)
} 
So understood, that is, as mental representation of a situation verifying some claims, carried out largely on a voluntary basis, imagination is everyday business. We simulate alternatives to reality in our mind, in order to explore what would and would not happen if they were realized. This can often help us to cope with reality itself, by improving future performance, allowing us to make contingency plans, etc. (see e.g. the works in Markman et al. (2009)).

Imagination is also distinguished, obviously, from (veridical) perception in that the target situations need not be real. To use a metaphor from Williamson (2007), in imagination our perceptions are left 'offline'. However, imagination is at times taken as involving some surrogate of sensory perception (typically, but not only, of the visual kind). For want of a better term for something that is close to perception but is not quite the real thing, it is common to use the 'quasi-' prefix: people speak of quasi-visual or quasi-auditory imaginings (see e.g. Gendler (2011)). Metaphors such as that of the mind's eye have been around for centuries.

Now whatever one makes of such loose characterizations, it seems to me that one should not take them as implying that the only imaginable scenarios are those that involve exclusively perceptual qualities (or, quasi-perceptual, whatever that means exactly). Otherwise, we could never imagine situations involving abstract objects or abstract features of concrete objects. But whether the imaginability of scenarios of these kinds entails their absolute possibility is precisely what is discussed in various debates on (HP). Thus, in such debates 'imagination' seems to be normally understood broadly enough. This is a point stressed also by Williamson (2007), who makes of imagination the key notion in a full-fledged counterfactual epistemology of metaphysical modality.

If such a rough characterization of the phenomenon at issue is sufficient, we can move on to the next act. That's where Kripke enters the stage.

\section{Kripkean Error Theory}

The post-Kripkean acceptance that, contrary to what much philosophical tradition believed, there are a posteriori necessities, may seem to hit (HP) hard. For identities such as those between Hesperus and Phosphorus or between water and $\mathrm{H}_{2} \mathrm{O}$, are empirical discoveries. Could we then not conceive of things as being otherwise, and so conceive the impossible? It seems easily imaginable that water may have turned out to have a different chemical constitution. At the time of The Meaning of Meaning, Putnam was clear:

We can perfectly well imagine having experiences that would convince us (and that would make it rational to believe that) water 
isn't $\mathrm{H}_{2} \mathrm{O}$. In that sense, it is conceivable that water isn't $\mathrm{H}_{2} \mathrm{O}$. It is conceivable but it isn't logically possible! Conceivability is no proof of logical possibility [...] Human intuition has no privileged access to metaphysical necessity. (Putnam (1975), p. 133)

However, things may be not so simple for the (HP)-denier. In Naming and Necessity, Kripke proposed a different diagnosis of the phenomenon, which according to Kung (2014) amounts to an attempt to explain the appearances away via a kind of error theory.

The key idea is that some imaginings are compatible with their authors' making errors in appreciating the represented content. Specifically, they may involve misidentifications. A posteriori necessary truths often give us an 'illusion of contingency': it may have turned out on empirical investigation, one thinks, that Hesperus is not Phosphorus or that water is not $\mathrm{H}_{2} \mathrm{O}$. Then these matters must be contingent. Kripke explains the illusion by resorting to intentional doppelgangers. We can think we are imagining a scenario in which water is not $\mathrm{H}_{2} \mathrm{O}$. What we actually intend, though, is a situation qualitatively identical to, or indiscernible from, one we may find ourselves in, and in which we face some fluid that has the same phenomenal features of water (say, a colourless, odourless, tasteless liquid, etc.), without being $\mathrm{H}_{2} \mathrm{O}$. We can also imagine having cherished that watery stuff with the name 'water'. But such an imagining is not the representation of an impossibility, that is, of (what we actually refer to as) water not being what it necessarily has to be. The illusion comes from misjudging our own representation, misidentifying that doppelganger of water with water.

To generalize: when we seem to imagine a situation $S$ falsifying an a posteriori necessity $P$, (a) we actually imagine a qualitatively indiscernible scenario $S_{1} \neq S$, such that (b) $S_{1}$ is possible and (thus) no falsifier of $P$, and (c) we confuse $S_{1}$ with $S .{ }^{10}$

Error theories do not have a great track record in philosophy, and I think this one is no exception. In the following Section, I will argue that the strategy does not generalize seamlessly - as it should, if it is the case that,

\footnotetext{
${ }^{10}$ Here is a passage of Naming and Necessity, in which Kripke appears to endorse such an error theory. It is the famous example of the table: "But whatever we imagine counterfactually having happened to [the table] other than what actually did, one thing we cannot imagine happening to this thing is that it, given that it is composed of molecules, should still have existed and not have been composed of molecules. We can imagine having discovered that it wasn't composed of molecules. But once we know that this is a thing composed of molecules - that this is the very nature of the substance of which it is made - we can't then, at least if the way I see it is correct, imagine that this thing might have failed to have been composed of molecules"(Kripke (1980), pp. 126-7).
} 
as required by (HP), we can never conceive the impossible. In the Section after that, I will argue that the strategy is based on a dubious view of conceivability-as-imagination.

\section{$5 \quad$ Does the Strategy Generalize?}

The strategy of redescribing represented wannabe-impossibilities as represented possibilities + misidentification, it seems to me, just won't work in all cases. One example, proposed in Wright (2002), is that of first-person counterpossible conjectures.

If Kripke is right, Wright claims, I am essentially a human being, and necessarily tied to my actual biological originators. But I can imagine myself as having been born from different parents. I can also imagine myself, say by putting myself at center stage in a fantasy story, as being an elf, an alien, a monkey. Can my imagining these scenarios, which essentialists usually consider metaphysically impossible, be explained away as my imagining possible situations involving an intentional doppelganger of mine, which I mistakenly identify with myself? It seems not, says Wright. For I do not individuate myself qua thinking subject by means of phenomenal, surface appearances, as I individuate water by its external appearances of colorless, tasteless liquid. When I imagine myself in a clearly possible counterfactual situation, such as my being in the Grand Canyon instead of Europe, "no mode of presentation of the self need feature in the exercise before it can count as presenting a scenario in which I am in the Grand Canyon" (Wright (2002), p. 436). The same holds for my counterpossible imagining myself as a monkey: this is not easily redescribable as my imagining a doppelganger which is a monkey, and mistakenly taking the substitute to be me. I imagine myself in this case as well.

Another area in which Kripkean redescription doesn't appear to be available has to do with mathematical conjectures and impossibilities. Firstly, it seems that we can conceive necessary truths of mathematics whose truth value we ignore as false, or vice versa. A mathematician may genuinely conceive that Goldbach's Conjecture (Every even integer larger than 2 is the sum of two primes) is wrong: she may also try to see what would follow from this. Suppose that the conjecture is indeed true. If mathematical necessity is unrestricted, then it is unrestrictedly impossible for some even number (larger than two) not to be the sum of two primes. Still, we cannot easily redescribe the mathematician's representation of the relevant impossibility as the conceiving of a false doppelganger of the conjecture. What could such a doppelganger be? As Priest claims: 
Take Goldbach's conjecture again. I have no difficulty in conceiving this, and no trouble conceiving its negation, though one of these is mathematically impossible. Indeed, mathematicians must be able to conceive these things, so that they understand what it is of which they are looking for a proof, or so that they can infer things from them, in an attempted reductio proof. (Priest (2005), p. 193)

Proven conjectures, such as Fermat's Last Theorem, make the case more vivid. Take a competent, but skeptic mathematician, who imagines she can find some mistake in Andrew Wiles' proof, or even direct counterexamples to the Theorem. The person understands the content of the Theorem pretty well: it's a simple claim on Diophantine equations. It is implausible to redescribe the situation as the mathematician's imagining counterexamples to an intentional duplicate of Fermat's Theorem. There appears to be no content-misidentification going on here. Wright also concludes from similar cases that "for a large class of impossibilities, there are still determinate ways things would seem if they obtained" (Wright (2002), p. 437).

\section{The Telescopic and Stipulative Views of Imagination}

It seems to me that the error theory comes with what Kung (2014) called a 'telescopic view' of imagination. In this view, 'seeing in imagination' is interpreted as an activity very close to physical, perceptual seeing (recall the aforementioned 'quasi-' jargon, often used in accounts of mental imagery). This appears to support (HP) by analogy: just as (veridical) visual perception only shows what is actual, so imaginative vision or quasi-vision only shows what is possible. When we imagine a scenario where $P$, we look with the metaphorical eye of the mind at a situation making $P$ true. What cannot happen is that such mental telescope has us look at the impossible: if the scenario shows up, it is there to be seen. What can happen is that we fail to appreciate exactly what scenario we are looking at. Imagining is like looking at a photograph: if we see a snapshot of a girl (leaving photoshop tricks aside), the girl must exist or have existed. But who's that girl? Valery or Laura?

Talk of 'telescopic view' by Kung is meant to remind us of Kripke arguing, notoriously, against a telescopic view of our access to worlds in Naming and Necessity. Kung thinks that Kripke's line of argumentation there applies against Kripke's own error theory for the imagining of impossibilities. 
The relevant context is the problem of transworld identification in the philosophy of possible worlds - a problem which, as far as I know, is originally due to Kaplan (1969). This is an epistemic issue, not to be confused with the problem of transworld identity (see Paul and Jago (2013), Mackie (2006)), which as far as I know is due to Chisholm (1967). The latter can itself be phrased in different ways (Divers (2002), Ch. 16, makes the relevant distinctions), but it is in any case an issue of (modal) metaphysics. The former has to do with how can we know whether we have a case of transworld identity in some sense or other.

In Kaplanian terms: which of the individuals in a possible world $w$ is the 'transworld heir' of an individual in a different possible world (say, the actual one, @)? Given our own Saul Kripke at @, we are supposed to carry out some investigation among the individuals in $w$, with the aim of locating the Kripke-representative there. The problem seems intractable, insofar as $w$ may include several individuals who resemble Kripke in various respects and can compete for the role. Here is one individual whose fingerprints and facial expression are indiscernible from those of our own beloved Kripke, but who never did philosophy and had a career as a drug dealer. Here's another one who does not quite look like Kripke, but who has written a book called Naming and Necessity, where he defends the view that there are necessary a posteriori truths, etc.

Scholars tend to consider transworld identity as a real issue (unless one is a counterpart theorist), and transworld identification as a pseudo-problem, precisely under the influence of Kripke. This pseudo-problem comes, for Kripke, from a purely qualitative conception of how worlds represent possibilities. Other worlds, says Kripke, are not something we glance at via the famous telescope. We need not represent alternative situations in purely qualitative terms: "generally, things aren't 'found out' about a counterfactual situation, they are stipulated." (Kripke (1980), p. 49), et cetera: the story is so well known that it hardly needs rehearsing (see also Plantinga (1974), p. 95; Chihara (1998)). ${ }^{11}$

I suggest, following Kung (2014) again, that imagination may work more like Kripkean stipulation than like a Kripkean telescope. It has, that is, an arbitrary labeling component. One need not deny that imagination in general

\footnotetext{
11 "There is something amiss when a claim of the type 'Suppose that Socrates had never gone into philosophy...' is met with the challenge to demonstrate how you know that it is Socrates that is the object of your supposition. The same might be said of the question how you know that the subject of the proposition that Socrates is a philosopher is the same as the subject of the proposition that Socrates was married [...]. The theme that unites the last two deflationary thoughts is that one can 'give' a possible world or a representational content in a non-qualitative way by relying on stipulation." (Divers (2002), p. 272)
} 
has a qualitative or phenomenological component as well, but the presence of the former component, the labeling or stipulation, seems to me enough to defeat (HP). In particular, the identity of the represented objects in an exercise of imagination can in general be stipulated - it does not need to be discovered.

I imagine Valery swimming in the Atlantic Ocean, and the phenomenology of the mental imagery can be such that the represented girl is relevantly similar to Valery: hair colour, eyes, body. But what makes my imagining count as a representation of a scenario in which Valery swims in the Ocean is that I label that represented woman as Valery. Now, as easily as I can imagine Valery as swimming in the Ocean - a possible scenario - I can represent Valery as having been born from different parents from the ones she actually has, or as a cleverly disguised robot. But the two latter scenarios, if Kripke is right, are metaphysically impossible.

Kung (2014) conjectures that such stipulative component is what gives to imagination its power to access the impossible. And in Towards NonBeing II, Priest is rather explicit in acknowledging this stipulative feature of imagination:

[W] hen I imagine that water is not $\mathrm{H}_{2} \mathrm{O}$ I am imagining something about water. The imagination is de re. In the same way, when I imagine that Sarah Palin was the US Vice President after the 2012 US election, I am imagining something about Palin. When I imagine that Routley found a box that was empty and not empty, it is him that I imagine. And when I imagine that 361 is a prime number (it isn't) I am imagining something about that very number. (Priest (2005), p. 195)

Now let us see how this stipulative view of conceivability as imagination is to be applied to (the interpretation of) the modal Meinongian theory. Given a condition $A[x]$, some object, $o$, can in principle be conceived by some cognitive agent $c$ as satisfying it. Then if $\Vdash$ is making true, $\Psi$ the relevant intentional state, and @ the actual world, we have @ $\Vdash c \Psi A[o]$. Even when $A[x]$ is the inconsistent ' $x$ is a round square', $c$ is really conceiving that the very object $o$ is round and square. And (QCP) guarantees that, at some world $w, o$ is a round square: $w \Vdash A[o]$.

What is not in our powers to stipulate is that $w$ be a possible world and, a fortiori, that $w=@$. In general, we cannot stipulate at which worlds objects have the properties they are characterized as having - whether these are possible worlds, and whether they include the actual one. This is true also when we embed explicit reference to worlds in the characterizing $A[x]$, 
e.g, via an 'actuality operator' that works as a world-pointer, pointing at @ (see Berto (2012), pp. 174-5 for the details). What one can fantasize about and what is or could be the case are at times severely different things. ${ }^{12}$

\section{Issues of Granularity}

The stipulative view can help us to address another objection to the imaginability of impossibilities. In order for a certain kind of intentional state to count as a representation of a situation verifying $P$, the objection goes, the situation at which $P$ must be represented in some relevant detail. To elucidate what this means with an example, here are two acts of imagination. First, I imagine a situation in which a bunch of mathematicians issue a press conference and declare that they have refuted Goldbach's Conjecture, thereby triggering admiration from the whole world. Second, I imagine building step by step a perfeclty detailed, valid proof, starting with Peano's axioms and ending with the negation of Goldach's Conjecture. Bracket the problem whether the exercise is mentally feasible (for the proof may be too complex for a human to mentally go through it with no external aid from paper, computers, or else).

In the latter case, the mental imagery is, in a sense, too fine-grained to count as a merely imagined, nonactual scenario: for if I actually go step by step through a sound refutation of the Conjecture, representing each step in full detail, then I have actually refuted the conjecture, if only in the private of my mind. On the other hand, the former case errs on the side of defect, by being too generic and relevantly disconnected a mental representation for it to count as my actually imagining that Goldach's conjecture is false. One could as well describe the envisaged scenario as one in which a bunch of folks make a press statement.

Thus, the objection goes, merely imagining that Goldbach's Conjecture is false without actually refuting it must be something in the middle between these two extremes. Which scale, or bunch of scales, must it be in the middle of, can be a matter of debate: detail of the mental imagery, topicality, relevance. How we measure and locate imaginings across the scales may be

\footnotetext{
12 "When I use the word 'Socrates' inside an explicitly worldly context, 'at w', or inside an implicitly worldly (modal or counterfactual) context [...] I do not thereby make it the case, nor do I come to know, that such a world is a possible world. It is this crucial point that underlies the complaint against [the claim that stipulative conceivability entails possibility]. It is one question how we know which objects are the objects of our de re modal thought and talk, and perhaps there stipulation has a legitimate role. It is another question altogether how we know what is modally true of those objects, and there stipulation has no legitimate role to play." (Divers (2002), p. 273)
} 
an open issue. The scales may even be orthogonal to each other, so that a unique score for a certain act of imagination may be unfeasible. But this is of limited importance for our purposes. What matters is that one cannot just generally stipulate that one has imagined a certain scenario, and be guaranteed to succeed independently from concerns of fine-grainedness. One can properly claim to have imagined a situation such that $P$ only when a sufficient level of structural detail in the mental imagery is reached, and that level may be generally unreachable for impossible $P$ 's.

I take it that Peter van Inwagen, a subscriber (it seems to me) to the telescopic view of imagination, has something like this objection in mind in the following passage:

In my view, we cannot imagine worlds in which there are naturally purple cows, time machines, transparent iron, a moon made of green cheese, or pure phenomenal colors in addition to those we know. Anyone who attempts to do so will either fail to imagine a world or else will imagine a world that only seems to have the property of being a world in which the thing in question exists. Can we imagine a world in which there is transparent iron? Not unless our imaginings take place at a level of structural detail comparable to that of the imaginings of condensed-matter physicists who are trying to explain, say, the phenomenon of superconductivity. (Van Inwagen (1998), p. 79)

The proper answer, I think, consists in distinguishing between (1) succeeding in thinking about a certain scenario, and (2) succeeding in gaining evidence that the scenario is possible. That it can be hard to succeed in the first sense due to granularity problems which are relevant for the issue of whether we can imagine the impossible, it seems to me, just presupposes the telescopic view of imagination. If imagination worked as a telescope, then indeed we may have reasons to doubt that one succeeds in imagining one situation rather than another, unless the imagining comes with a fine-grained enough level of structural detail in the relevant mental imagery. But that imagination works thus cannot simply be assumed, on pain of begging the question against the subscriber to the stipulative view. ${ }^{13}$

\footnotetext{
${ }^{13}$ There is a different issue concerning cases in which one supposedly fails to conceive what one meant to conceive, nicely pointed out to me by an anonymous referee. The issue has to do with one's lacking certain information which is plainly required for the stipulation to succeed. I'll just pick the referee's example: one thinks one imagines that Goldbach's Conjecture has been refuted, but one has misunderstood the content of Goldbach's Conjecture. In fact what the person labels thus is the claim that there is a greatest
} 
What we may not succeed in, when our imaginative exercise does not come with the right level of structural detail, is getting evidence that that is a possible scenario. The lack of detail is one of the things that can mislead us on the modal status of the envisaged situation. Again, the modal Meinongian who subscribes to the stipulative view of imagination need not deny that, when one's imaginative exercise is carried out at some appropriate level of structural detail, that gives defeasible evidence that the scenario is possible. But this is not what is required to save (HP), the stronger view that we just have no cognitive access to the impossible via our imagination.

\section{References}

Balcerak Jackson, M. (2016). On imagining, supposing and conceiving. In Kind, A. and Kung, P., editors, Knowledge Through Imagination. Oxford University Press, Oxford, forthcoming.

Berto, F. (2008). Modal meinoniganism for fictional objects. Metaphysics, 9:205-18.

Berto, F. (2012). Existence as a Real Property. Synthse Library, Springer, Dordrecht-New York.

Berto, F. (2013). Impossible worlds. The Stanford Encyclopedia of Philosophy.

Berto, F. and Schoonen, T. (2017). Conceivability and possibility: Some dilemmas for humeans. Synthese, On line first.

Byrne, A. (2007). Possibility and imagination. Philosophical Perspectives, $21: 125-44$.

Chalmers, D. (2002). Does conceivability entail possibility? In Gendler, T. and Hawthorne, J., editors, Conceivability and Possibility, pages 145-99. Oxford University Press, Oxford.

Chihara, C. (1998). The Worlds of Possibility. Oxford University Press, Oxford.

prime number. It seems to me that in this case one actually misdiscribes what one is conceiving, but that this failure is just orthogonal to the distinction between the stipulative and telescopic conceptions. In particular, it has little to do with 'insufficient granularity' in the sense relevant for van Inwagen's point: one can imagine in the greatest detail the standard proof that there is no largest prime while mistakenly labeling the proved claim as 'the negation of Goldbach's Conjecture'. 
Chisholm, R. (1967). Identity through possible worlds: Some questions. Noûs, 1:1-8.

Divers, J. (2002). Possible Worlds. Routledge, London and New York.

Fiocco, M. (2007). Conceivability, imagination and modal knowledge. Philosophy and Phenomenological Research, 74:364-80.

Gendler, T. (2011). Imagination. The Stanford Encyclopedia of Philosophy.

Gendler, T. and Hawthorne, J., editors (2002). Conceivability and Possibility. Oxford University Press, Oxford.

Hill, C. (1997). Imagininability, conceivability, possibility and the mind-body problem. Philosophical Studies, 87:61-85.

Jacquette, D. (1996). Meinongian Logic. The Semantics of Existence and Nonexistence. DeGruyter, Berlin and New York.

Jago, M. (2014). The Impossible. An Essay on Hyperintensionality. Oxford University Press, Oxford.

Kaplan, D. (1969). Transworld heirlines. In Loux, M., editor, The Possible and the Actual, pages 88-109. Cornell University Press, Ithaca.

Kiourti, I. (2010). Real Impossible Worlds: the Bounds of Possibility. PhD thesis, IUniversity of St Andrews.

Kripke, S. (1980). Naming and Necessity. Blackwell, Oxford.

Kung, P. (2010). Imagining as a guide to possibility. Philosophy and Phenomenological Research, 81:620-63.

Kung, P. (2014). You really do imagine it: Against error theories of imagination. Nous, 50:90-120.

Mackie, P. (2006). How Things Might Have Been: Individuals, Kinds, and Essential Properties. Oxford University Press, Oxford.

Markman, K., Klein, W., and Surh, J., editors (2009). Handbook of Imagination and Mental Simulation. Taylor and Francis, New York.

Nichols, S. and Stich, S. (2003). Mindreading. An Integrated Account of Pretence, Self-Awareness, and Understanding Other Minds. Oxford University Press, Oxford. 
Nolan, D. (2013). Impossible worlds. Philosophy Compass, 8:360-372.

Parsons, T. (1980). Nonexistent Objects. Yale University Press, New haven, Conn.

Paul, L. and Jago, M. (2013). Transworld identity. Stanford Encyclopedia of Philosophy, https://plato.stanford.edu/entries/identity-transworld/.

Plantinga, A. (1974). The Nature of Necessity. Clarendon Press, Oxford.

Priest, G. (1998). What is so bad about contradictions? Journal of Philosophy, 95:410-26.

Priest, G. (2005). Towards non-Being. The Logic and Metaphysics of Intentionality. Oxford University Press, Oxford, 2nd expanded ed. 2016.

Putnam, H. (1975). Mind, Language and Reality. Philosophical Papers. Cambridge University Press, Cambridge.

Quine, W. (1948). On what there is. Review of Metaphysics, 48:21-38.

Rantala, V. (1982). Impossible world semantics and logical omniscience. Acta Philosophica Fennica, 35:106-115.

Rapaport, W. (1978). Meinongian theories and a russellian paradox. Noûs, 12:153-180.

Routley, R. (1980). Exploring Meinong's Jungle and Beyond. RSSS Australian National University, Canberra.

Stoljar, D. (2007). Two conceivability arguments compared. Proceedings of the Aristotelian Society, 107:27-44.

Van Inwagen, P. (1998). Modal epistemology. Philosophical Studies, 92:6784.

Wansing, H. (2015). Remarks on the logic of imagination. a step towards understanding doxastic control through imagination. Synthese, On line first.

Williamson, T. (2007). The Philosophy of Philosophy. Blackwell, Oxford.

Wittgenstein, L. (1922). Tractatus Logico-Philosophicus. Routledge Kegan Paul, London. 
Wright, C. (2002). The conceivability of naturalism. In Gendler, T. and Hawthorne, J., editors, Conceivability and Possibility, pages 401-39. Oxford University Press, Oxford.

Yablo, S. (1993). Is conceivability a guide to possibility? Philosophy and Phenomenological Research, 53:1-42.

Zalta, E. (1983). Abstract Objects. An Introduction to Axiomatic Metaphysics. Reidel, Dordrecht.

Zalta, E. (1997). A classically-based theory of impossible worlds. Notre Dame Journal of Formal Logic, 38:640-660. 